\title{
Involvement of non-Helicobacter pylori helicobacter infections in Helicobacter pylori-negative gastric MALT lymphoma pathogenesis and efficacy of eradication therapy
}

\author{
Hidehiko Takigawa ${ }^{1} \cdot$ Ryo Yuge $^{1} \cdot$ Satoshi Masaki $^{2} \cdot$ Rina Otani $^{3} \cdot$ Hiroki Kadota $^{3} \cdot$ Toshikatsu Naito $^{3}$. \\ Ryohei Hayashi $^{1} \cdot$ Yuji Urabe $^{4}$. Shiro Oka ${ }^{3}$. Shinji Tanaka ${ }^{1} \cdot$ Kazuaki Chayama $^{3} \cdot$ Yasuhiko Kitadai $^{2} \mathbb{D}$
}

Received: 27 December 2020 / Accepted: 12 February 2021 / Published online: 27 February 2021

(c) The International Gastric Cancer Association and The Japanese Gastric Cancer Association 2021

\begin{abstract}
Background Eradication therapy is known to be effective against Helicobacter pylori-positive gastric MALT lymphoma but predicting the efficacy of eradication therapy against Helicobacter pylori-negative gastric MALT lymphoma is difficult. Recent reports have shown that non-Helicobacter pylori helicobacter infections induce gastric MALT lymphoma, and we aimed to clarify whether non-Helicobacter pylori helicobacter infections are associated with the efficacy of eradication therapy.

Methods We analyzed eradication therapy as a first-line treatment for 182 cases of gastric MALT lymphoma, classified according to Helicobacter pylori infection and API2-MALT1 mutation status. We also evaluated the non-Helicobacter pylori helicobacter infection status in 29 Helicobacter pylori-negative cases via PCR with DNA extracted from paraffin-embedded biopsy tissues. Finally, we analyzed the relationship between non-Helicobacter pylori helicobacter infection status and eradication therapy outcome.

Results The API2-MALT1 mutation was observed in 13/182 patients (7.1\%), none of whom were cured by eradication therapy. Helicobacter pylori-negative cases had a significantly higher non-Helicobacter pylori helicobacter infection rate than Helicobacter pylori-positive cases $(16 / 29,55 \%$ vs. 3/29, 10\%; $P<0.05)$. Among the Helicobacter pylori-negative cases, non-Helicobacter pylori helicobacter-positive cases had a significantly higher complete response rate than non-Helicobacter pylori helicobacter-negative cases $(12 / 16,75 \%$ vs. $3 / 13,23 \% ; P<0.05)$.

Conclusion Helicobacter pylori-negative and API2-MALT1-negative gastric MALT lymphoma cases exhibited a high rate of non-Helicobacter pylori helicobacter infections, which may have contributed to the success of eradication therapy. Therefore, we recommend eradication therapy as a first-line treatment for non-Helicobacter pylori helicobacter-positive gastric MALT lymphoma.
\end{abstract}

Keywords Non-Helicobacter pylori helicobacter · Gastric MALT lymphoma · Helicobacter pylori · API2-MALT1 · Eradication therapy

Yasuhiko Kitadai

kitadai@pu-hiroshima.ac.jp

1 Department of Endoscopy, Hiroshima University Hospital, Hiroshima 734-0037, Japan

2 Department of Health and Science, Prefectural University of Hiroshima, 1-1-71, Ujinahigashi, Minami-ku, Hiroshima 734-8558, Japan

3 Department of Gastroenterology and Metabolism, Hiroshima University, Hiroshima 734-0037, Japan

4 Division of Regeneration and Medicine Center for Translational and Clinical Research, Hiroshima University Hospital, Hiroshima 734-0037, Japan

\section{Introduction}

The stomach is the most common extranodal site of nonHodgkin lymphoma, representing 30-40\% of all extranodal lymphomas as well as 4-20\% of all non-Hodgkin lymphomas, and approximately $5 \%$ of primary gastric neoplasms $[1,2]$. Among primary gastric lymphomas, marginal zone B-cell lymphoma of the mucosa-associated lymphoid tissue (MALT) is the most common histological subtype [3]. Helicobacter pylori $(\mathrm{Hp})$ infection and the API2-MALT1 chimeric gene transcript have been established as causes of gastric MALT lymphoma [4]. Additionally, non-Helicobacter 
pylori helicobacter (NHPH) infections have been recently reported as another cause of gastric MALT lymphoma [5-7].

NHPHs are zoonotic and transmitted from pigs, dogs, and cats to humans [8]. Nakamura et al. [9] reported that NHPH infection was found in $17.3 \%$ of gastritis cases and $33.3 \%$ of gooseflesh gastritis cases. Another report has shown an association between NHPH infection and gastric ulcers [10]. There is a lack of evidence demonstrating an association between gastric cancer and NHPH infections. Since NHPHs have less affinity for the epithelium of gastric mucosa than $H p$ [11-13], their effect on carcinogenesis may be lower than that of $H p$ as previously reported [9]. However, a recent report has shown that patients with NHPH infections develop gastric MALT lymphoma more often than those with $H p$ infections [14]. Approximately 25\% of NHPH-infected mice develop low-grade MALT lymphoma, compared with $0 \%$ of the control group [15]. Culturing NHPHs is reported to be more difficult than culturing $\mathrm{Hp}$, and diagnostic methods for NHPH infections have not yet been clinically established. Goji et al. reviewed 26 articles and calculated that the sensitivities of the diagnostic methods equivalent to those used for diagnosing $H p$ infection, including the rapid urease test, urea breath test, blood antibody analysis, immunohistochemical analysis, and stool antigen analysis, were only $40.0 \%$, $14.8 \%, 23.1 \%, 40.0 \%$, and $0 \%$, respectively [16]. Histological techniques and genetic diagnosis based on PCR are the most effective methods for diagnosing NHPH infections [16], and the prevalence of NHPH infections determined using these methods was reported to be much lower than that of $H p$, ranging from 0.1 to $6 \%[6,17]$.

The genome sequences of five NHPH species based on 16S rRNA gene sequencing have been recently clarified [18-22]. Accompanied by the emergence of PCR-based diagnostic methods, the accuracy of NHPH infection diagnosis may be improved. Recently, Nakamura et al. [9] reported that the NHPH infection rate is over $20 \%$ in chronic gastritis, gastric ulcer, duodenal ulcer, and gastric MALT lymphoma without $H p$ infection, based on the results of PCR analysis. We also previously succeeded in diagnosing $H$. suis infections in gastric MALT lymphoma cases using PCR methods with DNA extracted from formalin-fixed paraffin-embedded (FFPE) tissues [23].

According to the National Comprehensive Cancer Network guidelines, regardless of the presence of the API2MALT1 mutation, eradication treatment and radiation therapy (RT) are the first choices for treating $\mathrm{Hp}(+)$ and $H p(-)$ gastric MALT lymphoma cases, respectively. However, a recent review reported that eradication therapy is expected to be effective to some extent even in $\mathrm{Hp}(-)$ cases. Therefore, it might be worthwhile to consider eradication therapy as a first-line treatment for $H p(-)$ cases because it is less invasive than RT [24, 25]. Choi et al. [25] reported that eradication therapy has an extremely poor efficacy against
API2-MALT1 (+) cases regardless of $H p$ infection status. According to a review article by Asano et al. the complete response (CR) rate achieved using eradication therapy in $\mathrm{Hp}$ ([25]) gastric MALT lymphoma cases ranges from 0 to $83 \%$ (an average of $28 \%$, which is lower than that achieved in $H p$ $(+)$ cases) $[24,26]$.

Based on these reports, eradication therapy is considered unlikely to be effective against API2-MALT1 $(+)$ cases but likely to be effective against most API2-MALT1 (-) $H p(+)$ cases and possibly effective against some API2-MALT1 (-) $H p(-)$ cases. However, it is difficult to predict the efficacy of eradication therapy against API2-MALT1 (-) $H p(-)$ cases before an initial course of eradication therapy is administered. Therefore, it would be clinically valuable to identify a predictive marker for the efficacy of eradication therapy in API2-MALT1 (-) $H p(-)$ gastric MALT lymphoma cases.

Here, we classified gastric MALT lymphoma cases according to API2-MALT1 mutation status, $H p$ infection status, and NHPH infection status and evaluated the clinical outcomes of eradication therapy. We aimed to clarify whether one of these conditions might serve as a predictive marker for the efficacy of eradication therapy against gastric MALT lymphoma, especially among API2-MALT1 (-) $\mathrm{Hp}$ $(-)$ cases.

\section{Materials and methods}

\section{Patients}

From 1996 to 2016, 210 patients were diagnosed with localized gastric MALT lymphoma and followed up at the Hiroshima University Hospital after treatment. Among this cohort, we analyzed the clinicopathological features of 182 patients who underwent eradication therapy as a first-line treatment and were followed for more than one year. Gastric MALT lymphoma was diagnosed according to the criteria of the World Health Organization [27] and if symptoms were consistent with grade 4 or 5 of the Wotherspoon histological scoring system [28]. Our study included patients with atypical lymphocytes that were positive for $\mathrm{CD} 20$ and negative for CD3 and CD79a. After treatment, histopathological evaluation was performed using the Group d'Etude des Lymphomes deI'Adulte (GELA) grading system [29]. The CR of lymphoma was defined as complete histological response $(\mathrm{ChR})$ or probable minimal residual disease (pMRD) in the Ann Arbor staging system [30]. Tumor stage was evaluated via clinical examination, full blood count, biochemical analysis, and cervical, pectoral, abdominal, and pelvic computed tomography scans.

All cases were examined for $H p$ infection and the presence of the API2-MALT1 chimeric transcript. $H p$ infection was evaluated serologically using the anti- $H p \operatorname{IgG}$ antibody. 
Successful eradication was confirmed using the urea breath test. FISH analysis was conducted by LSI Medience Corporation (Tokyo, Japan) on fresh biopsy samples from all patients to detect the API2-MALT1 chimeric transcript as previously described [31, 32]. Background information of the 182 patients included in the study is presented in Table 1.

Consequently, among these 182 cases, we focused on NHPH infection in API2-MALT1 (-) $H p(-)$ gastric MALT lymphoma. There were 29 cases of API2-MALT1 (-) $H p$ (-) gastric MALT lymphoma and we examined NHPH infection all of these cases. As controls, we randomly

Table 1 Background information of the 182 patients of localized gastric MALT lymphoma analyzed in this study

\begin{tabular}{lc}
\hline & $\begin{array}{l}\text { Localized gastric } \\
\text { MALT lymphoma } \\
(n=182)\end{array}$ \\
\hline $\begin{array}{l}\text { Median age (range) } \\
\text { Sex }\end{array}$ & $62(20-89)$ \\
Male & $103(57 \%)$ \\
Female & $79(43 \%)$ \\
HP infection & $148(81 \%)$ \\
Positive & $34(19 \%)$ \\
Negative & $13(7 \%)$ \\
API2-MALT1 chimeric gene transcript & $169(93 \%)$ \\
Positive & \\
Negative & $59(32 \%)$ \\
Location in the stomach & $90(49 \%)$ \\
U & $33(19 \%)$ \\
M & \\
L & $87(48 \%)$ \\
Number of lesions & $95(52 \%)$ \\
Single & \\
Multiple &
\end{tabular}

HP Helicobacter pylori, $U$ upper part of stomach, $M$ middle part of stomach, $L$ lower part of stomach selected $29 H p(+)$ cases, which was an equal number as the API2-MALT1 (-) $H p(-)$ cases, from $140 H p(+)$ cases, in a similar manner as previously reported [33].

MALT lymphoma was said to exhibit CR when the absence of lymphoma was confirmed both macroscopically and pathologically. The characteristics, treatments, and outcomes of the patients were analyzed retrospectively. After eradication therapy, all cases were followed up endoscopically every three months for one year and annually thereafter.

\section{Eradication therapy}

To eradicate Helicobacter species, patients with gastric MALT lymphoma received a one-week course of orally administered lansoprazole ( $60 \mathrm{mg} /$ day), vonoprazan $(40 \mathrm{mg} /$ day), amoxicillin (1500 mg/day), and clarithromycin (400 mg/day) twice a day. In this study, treatment with this regimen was defined as "eradication therapy" regardless of $H p$ infection status.

\section{DNA extraction and gastric Helicobacter species-specific PCR assay}

Paraffin block sections $(10 \times 10 \mu \mathrm{m})$ were collected in microtubes, and DNA was extracted using the Gene Read DNA FFPE Kit (Qiagen Japan, Tokyo, Japan) following the manufacturer's instructions. PCR amplification of the urease gene from NHPH species (H. suis, H. bizzozeronii, $H$. felis, H. salomonis, and H. heilmannii s.s.) was performed using species-specific primers according to a previous report (Table 2) [34, 35]. PCR reactions were conducted using the buffer and DNA polymerase from KOD FX Neo (TOYOBO, Osaka, Japan) according to the manufacturer's instructions. The PCR amplification of H. suis, H. bizzozeronii, H. felis, and $H$. heilmannii was performed under the following conditions: 5 min of preincubation at $95{ }^{\circ} \mathrm{C}$ followed by 40

Table 2 Primers used for non-Helicobacter pylori helicobacter detection

\begin{tabular}{|c|c|c|c|c|c|}
\hline Target gene & Target species & Primer sequences (F: forward, R: reverse) & $\begin{array}{l}\text { Annealing tem- } \\
\text { perature }\left({ }^{\circ} \mathrm{C}\right)\end{array}$ & Cycle number & $\begin{array}{l}\text { Fragment } \\
\text { size (bp) }\end{array}$ \\
\hline \multirow[t]{2}{*}{ ureA } & H. suis & F: CACCACCCCGGGGAAGTGATCTTG & 60 & 40 & 253 \\
\hline & & R: CTACATCAATCAAATGCACGGTTTTTTCTTCG & & & \\
\hline \multirow[t]{2}{*}{ ureA } & H. bizzozeronii & F: CGCTTTGAACCCGGTGAGAAAA & 60 & 40 & 172 \\
\hline & & R: TATCGCAACCGCAATTCACAACA & & & \\
\hline \multirow[t]{2}{*}{ ureB } & H. felis & F: TCCCACTACCGGGGATCGTG & 60 & 40 & 350 \\
\hline & & R: CAGCGGTTACAATCAAGCCCTCA & & & \\
\hline \multirow[t]{2}{*}{ ureAB } & H. salomonis & F: CTTTGGGTCTGTGCCTGCCTG & 62 & 40 & 219 \\
\hline & & R: CATCGCGGATAGTCTTACCGCCT & & & \\
\hline \multirow[t]{2}{*}{ ureA } & H. heilmannii s.s & F: CTTTCTCCTGGTGAAGTGATTCTC & 60 & 40 & 368 \\
\hline & & R: CAGTTGATGGTGCCAAAG & & & \\
\hline
\end{tabular}


cycles of $30 \mathrm{~s}$ at $94{ }^{\circ} \mathrm{C}, 30 \mathrm{~s}$ at $60{ }^{\circ} \mathrm{C}$, and $30 \mathrm{~s}$ at $72{ }^{\circ} \mathrm{C}$. A final extension was performed for $7 \mathrm{~min}$ at $72{ }^{\circ} \mathrm{C}$. The $H$. salomonis amplification conditions were $5 \mathrm{~min}$ of preincubation at $95{ }^{\circ} \mathrm{C}$ followed by 40 cycles of $30 \mathrm{~s}$ at $94{ }^{\circ} \mathrm{C}, 30 \mathrm{~s}$ at $62{ }^{\circ} \mathrm{C}$, and $30 \mathrm{~s}$ at $72{ }^{\circ} \mathrm{C}$. A final extension was performed for $7 \mathrm{~min}$ at $72{ }^{\circ} \mathrm{C}$ according to previous report [35].

\section{Statistical analysis}

Between-group differences were evaluated using Mann-Whitney $U$ test for quantitative data and the $\chi^{2}$ test for categorical data. Fisher's exact test was used, as required. All tests were two-sided, and a $P$ value $<0.05$ was considered statistically significant. All analyses were performed using EZR (Saitama Medical Centre, Jichi Medical University, Saitama, Japan) [36].

\section{Results}

\section{Efficacy of eradication therapy against API2-MALT1 $(+)$ gastric MALT lymphoma}

We first examined the expression of the API2-MALT1 chimeric transcript in 182 patients who underwent $\mathrm{Hp}$ eradication therapy as a first-line treatment at Hiroshima University Hospital. Thirteen cases $(13 / 182 ; 7.1 \%)$ were positive for API2-MALT1. Hp eradication therapy was not effective in any of the cases, regardless of $H p$ infection status. RT was chosen as a second-line therapy, and CR was obtained in all cases. Among the 169 API2-MALT1 (-) cases, 140 were infected with $H p$. The CR rates after eradication therapy was administered to the $H p(+)$ and (-) groups were $81.2 \%$ $(113 / 140)$ and 52\% (15/29), respectively. Although the CR rate was significantly lower among $H p(-)$ cases (Fig. 1), eradication therapy was effective in half of the $H p(-)$ cases.

\section{Comparison of clinicopathological features between $H p(-)$ and $H p(+)$ gastric MALT lymphoma}

Next, we determined the NHPH infection status in API2MALT1 (-) $H p(-)$ cases using PCR analysis. Out of 29 $H p(-)$ cases, 16 (H. suis alone: 5 cases; H. bizzozeronii alone: 8 cases; double-infection of $H$. suis and $H$. bizzozeronii: 3 cases) were positive for an NHPH infection. To compare the prevalence of NHPH infections between $\mathrm{Hp}$ $(-)$ and $H p(+)$ cases, we conducted PCR analysis of 29 $\mathrm{Hp}(+)$ cases that were randomly selected from the $140 \mathrm{Hp}$ (+) API2-MALT1(-) cases. Out of the $29 H p(+)$ cases, only 3 (H. bizzozeronii alone: 2 cases; double-infection of $H$. suis and $H$. bizzozeronii: 1 case) were positive for an NHPH infection.

The clinicopathological features of the $H p(-)$ and $H p$ $(+)$ cases are shown in Table 3 . There were no significant differences between the two groups in terms of the mean age, sex, number of lesions (single or multiple), lesion localization, or tumor morphology. The NHPH infection rate was significantly higher in the $H p(-)$ group than in the $H p(+)$ group $(16 / 29,55 \%$ vs. $3 / 29,10 \% ; P<0.05)$. The $\mathrm{CR}$ ratio achieved by eradication therapy was significantly lower in the $H p(-)$ group than in the $H p(+)$ group $(15 / 29,52 \%$ vs. $24 / 29,83 \% ; P<0.05)$. Severe atrophy was observed more often in the $H p(+)$ group than in the $H p(-)$ group $(20 / 29$, $69 \%$ vs. $1 / 29,3 \% ; P<0.05$ ) (Table 3 ).

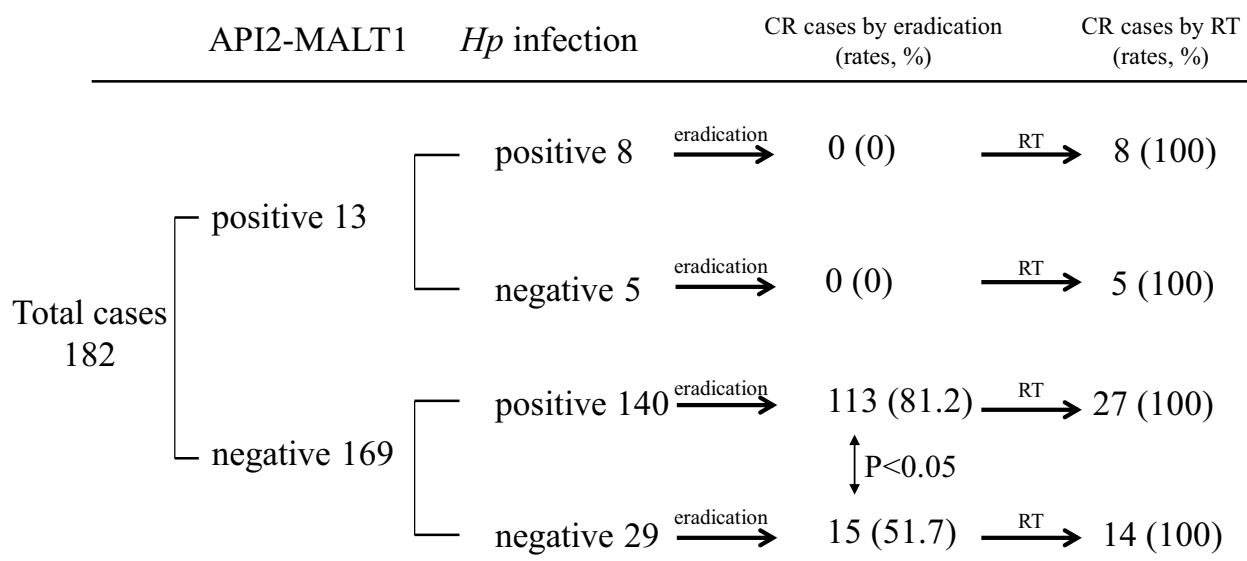

Fig. 1 Results of treating gastric MALT lymphoma with eradication therapy. Flow chart of treatment administered to patients classified by API2-MALT1 chimeric transcript and $H p$ infection status. All cases underwent eradication therapy as a first-line therapy. Non-responders to eradication therapy achieved CR after RT. There were 13 API2MALT1 (+) cases. None of these patients achieved CR after eradi- cation therapy but all did achieve CR after subsequent RT. Among API2-MALT1 (-) cases, $81.2 \%$ of $H p(+)$ cases and $51.7 \%$ of $H p(-)$ cases achieved CR after eradication therapy. Abbreviations: API2MALT1, API2-MALT1 chimeric transcript; Hp, Helicobacter pylori; $\mathrm{CR}$, complete response; RT, radiation therapy 
Table 3 Comparison between Helicobacter pylori-positive and Helicobacter pylori-negative cases in API2-MALT1-negative gastric MALT lymphoma

\begin{tabular}{|c|c|c|c|}
\hline & $\begin{array}{l}\mathrm{HP}+ \\
(n=29)\end{array}$ & $\begin{array}{l}\mathrm{HP}- \\
(n=29)\end{array}$ & $P$ value \\
\hline Median age (range) & $64(45-82)$ & $60(32-88)$ & 0.4483 \\
\hline \multicolumn{4}{|l|}{ Sex } \\
\hline Male & $12(41 \%)$ & $12(41 \%)$ & \multirow[t]{2}{*}{1.00} \\
\hline Female & $17(59 \%)$ & $17(59 \%)$ & \\
\hline \multicolumn{4}{|l|}{ NHPH infection status } \\
\hline Positive & $3(10 \%)$ & $16(55 \%)$ & \multirow[t]{2}{*}{$0.0003 *$} \\
\hline Negative & $26(90 \%)$ & $13(45 \%)$ & \\
\hline \multicolumn{4}{|c|}{ Effect of eradication therapy } \\
\hline $\mathrm{CR}$ & $24(83 \%)$ & $15(52 \%)$ & \multirow[t]{2}{*}{$0.01291 *$} \\
\hline $\mathrm{NC}$ & $5(17 \%)$ & $14(48 \%)$ & \\
\hline \multicolumn{4}{|l|}{ Number of lesions } \\
\hline Single & $11(38 \%)$ & $10(34 \%)$ & \multirow[t]{2}{*}{1.00} \\
\hline Multiple & $18(62 \%)$ & $19(66 \%)$ & \\
\hline \multicolumn{4}{|l|}{ Location } \\
\hline $\mathrm{U}$ & $4(14 \%)$ & $3(10 \%)$ & \multirow[t]{2}{*}{1.00} \\
\hline $\mathrm{M} / \mathrm{L}$ & $25(86 \%)$ & $26(90 \%)$ & \\
\hline \multicolumn{4}{|l|}{ Morphological type } \\
\hline Superficial & $27(93 \%)$ & $25(86 \%)$ & 0.6664 \\
\hline Nodular & $0(0 \%)$ & $3(11 \%)$ & 0.2357 \\
\hline Other & $2(7 \%)$ & $1(3 \%)$ & 1.00 \\
\hline \multicolumn{4}{|c|}{ Atrophy of gastric mucosa } \\
\hline No atrophy & $0(0 \%)$ & $24(83 \%)$ & $0.0001^{*} \dagger$ \\
\hline Closed type atrophy & $9(31 \%)$ & $4(14 \%)$ & $0.2070^{\dagger}$ \\
\hline Open type atrophy & $20(69 \%)$ & $1(3 \%)$ & $0.0001^{*, \dagger}$ \\
\hline
\end{tabular}

$H P$ Helicobacter pylori, $C R$ complete response, $N C$ no change, $U$ upper part of stomach, $M$ middle part of stomach, $L$ lower part of stomach

*Statistically significant

${ }^{\dagger}$ The significance level $(P<0.05 / 3)$ was adjusted with the Bonferroni correction for multiple comparisons

\section{Comparison of clinicopathological features between NHPH (-) and NHPH (+) gastric MALT lymphoma}

The clinicopathological features of $16 \mathrm{NHPH}(+)$ and 13 NHPH (-) cases [all $H p(-)$ ] are shown in Table 4. Of note, the NHPH (+) cases tended to have a nodular morphological appearance. There were no significant differences between the two groups in terms of sex, number of lesions, or tumor location. Patients in the NHPH $(+)$ group were significantly younger than those in the NHPH (-) group $(58,32$ to 71 vs. 66,55 to $88 ; P<0.05)$. Notably, in the NHPH $(+)$ group, the CR rate achieved by eradication therapy was significantly higher than that in the NHPH (-) group $(12 / 16,75 \%$ vs. $3 / 13,23 \% ; P<0.05)$. There was no difference in the degree of background mucosal atrophy
Table 4 Comparison between NHPH-positive and NHPH-negative cases in gastric MALT lymphoma being negative for API2-MALT1 and Helicobacter pylori

\begin{tabular}{llll}
\hline & $\begin{array}{l}\mathrm{NHPH}+ \\
(n=16)\end{array}$ & $\begin{array}{l}\text { NHPH- } \\
(n=13)\end{array}$ & $P$ value \\
\hline $\begin{array}{l}\text { Median age (range) } \\
\text { Sex }\end{array}$ & $58(32-71)$ & $66(55-88)$ & $0.048^{*}$ \\
Male & $6(38 \%)$ & $6(43 \%)$ & 0.7163 \\
Female & $10(62 \%)$ & $7(57 \%)$ & \\
Effect of eradication therapy & & & \\
CR & $12(75 \%)$ & $3(23 \%)$ & $0.00921^{*}$ \\
NC & $4(25 \%)$ & $10(77 \%)$ & \\
Number of lesions & & & \\
Single & $5(31 \%)$ & $5(38 \%)$ & 0.714 \\
Multiple & $11(69 \%)$ & $8(62 \%)$ & \\
Location & & & \\
U & $1(6 \%)$ & $2(15 \%)$ & 0.5731 \\
M/L & $15(94 \%)$ & $11(85 \%)$ & \\
Morphological type & & & \\
Superficial & $13(81 \%)$ & $12(92 \%)$ & $0.6059^{\dagger}$ \\
Nodular & $3(19 \%)$ & $0(0 \%)$ & $0.0481^{\dagger}$ \\
Other & $0(0 \%)$ & $1(8 \%)$ & $0.4483^{\dagger}$ \\
Atrophy of gastric mucosa & & & \\
No atrophy & $14(87 \%)$ & $10(77 \%)$ & $0.6322^{\dagger}$ \\
Closed type atrophy & $2(13 \%)$ & $2(15 \%)$ & $1.00^{\dagger}$ \\
Open type atrophy & $0(0 \%)$ & $1(8 \%)$ & $0.4483^{\dagger}$ \\
\hline
\end{tabular}

$N H P H$ non-Helicobacter pylori helicobacter, $C R$ complete response, $N C$ no change, $U$ upper part of stomach, $M$ middle part of stomach, $L$ lower part of stomach

* Statistically significant

The significance level $(P<0.05 / 3)$ was adjusted with the Bonferroni correction for multiple comparisons

between NHPH (-) and NHPH (+) groups in the $29 \mathrm{Hp}$ $(-)$ cases.

\section{Discussion}

In this study, we evaluated the prevalence of NHPH infections and investigated whether the efficacy of eradication therapy against gastric MALT lymphoma was associated with the API2-MALT1 gene mutation, $H p$ infection status, or NHPH infection status. We demonstrated that $H p(-)$ gastric MALT lymphoma cases had a significantly higher NHPH infection rate than $H p(+)$ cases. For $H p(-)$ cases, some reports recommend RT as a first-line treatment due to the low response rate to eradication therapy. In contrast, others suggest eradication therapy prior to RT because of the invasiveness of RT. There is a lack of consensus regarding this issue. Eradication therapy administered to all patients with $H p(-)$ cases in this study achieved remission in $51.7 \%$ 
of API2-MALT1 (-) cases. The efficacy rate of eradication therapy in $H p(-)$ cases reportedly ranges from 0 to $83 \%$ (average: 28\%) [24]. The difference between our data and those of previous reports may be attributed to our exclusion of API2-MALT1 ( +) cases. Furthermore, eradication therapy was more effective among API2-MALT1 $(-)$ and HP ( $(-)$ cases that were NHPH (+). However, among the $\mathrm{NHPH}(+)$ group, 4/16 cases of gastric MALT lymphoma were not cured by eradication therapy. As for these 4 cases, we additionally examined the status of NHPH infection after eradication therapy. Interestingly, NHPH infection was successfully eradicated in all 4 cases (data not shown). Nakamura et al. [9] reported $100 \%$ eradication of NHPH in 45 patients, showing that eradication therapy seems to be highly effective against NHPH. The reason MALT lymphoma was not cured in those 4 cases may not be related to unsuccessful eradication of NHPH. Although speculative, it is possible that bacteria other than NHPH, or other unknown factors, could be partially associated with the pathogenesis of MALT lymphoma. On the other hand, among the $H p(-) \mathrm{NHPH}$ $(-)$ gastric MALT lymphoma cases, there were a few cases $(3 / 13 ; 23 \%)$ which were cured by eradication therapy. In this study, we investigated the five known NHPH species that have been reported to infect humans [8]. However, it is quite possible that other NHPHs that are not known to infect humans, or other unidentified species, may have been partially involved in the development of $H p(-)$ NHPH (-) gastric MALT lymphoma, for which eradication therapy was effective.

Regarding the API2-MALT1 (+) cases, our results were consistent with previous reports [24, 25]. Eradication therapy was ineffective regardless of $H p$ infection status, and it was favorable to precede treatment with RT. Among API2MALT1 (-) cases, those that were $H p(+)$ had a high rate of response to eradication therapy. Thus, as has been reported, we believe that eradication therapy is beneficial as a firstline treatment for $H p(+)$ cases. In $H p(-)$ cases, although the rate of response to eradication therapy was low, some patients did achieve CR. In these cases, selecting RT as the first-line therapy may be an overtreatment.

The prevalence of NHPH infections is much lower than that of $H p[6,13,17,37,38]$. However, our study demonstrated that $H p(-)$ gastric MALT lymphoma cases had an extremely high NHPH infection rate. Although an association between NHPH and gastric MALT lymphoma has been previously reported $[5,39]$, few studies have measured the NHPH infection rate in as large a sample as that examined in this study. In the present study, we focused on NHPH infection in API2-MALT1 (-) Hp (-) gastric MALT lymphoma with the goal of identifying a potential predictive marker. Thus, as for API2-MALT1 $(-) H p(+)$ gastric MALT lymphoma, we examined NHPH infection in randomly selected cases. In gastric MALT lymphoma as a whole, there is an interesting report from Japan that showed that the NHPH infection rate is $23.9 \%(11 / 46)$ [9]. Conventionally, frozen biopsy specimens are used to obtain DNA from the gastric mucosa for laboratory studies, and PCR-based diagnostic methods are relatively easy. However, frozen specimens are not routinely prepared from biopsies in clinical settings, and this limitation may have caused difficulties in evaluating the NHPH infection rate in large samples of gastric MALT lymphoma cases. In this study, the DNA used for PCR analysis was extracted from FFPE tissues. This technique may be more useful than extracting DNA from frozen sections, due to the widespread clinical availability of FFPE tissues.

Severe atrophy was significantly more often in $H p(+)$ cases than in $H p(-)$ cases. There was no difference in the degree of background mucosal atrophy when comparing patients with and without NHPH infection in the $29 \mathrm{Hp}(-)$ cases. Although there are reports showing that NHPH has only slight affinity for the epithelium and does not cause atrophy [16, 40, 41], NHPH infection has been found in $17.3 \%$ of patients with chronic gastritis [9]. It is still controversial whether NHPH infection causes atrophy. No clear association was found between atrophy and NHPH infection in this study. Atrophy was mild, regardless of whether NHPH infection was present.

We previously analyzed the endoscopic characteristics of gastric MALT lymphoma in patients infected with NHPH. Along with Nakamura et al., we reported that NHPH infections cause nodular gastritis and that gastric MALT lymphoma has a nodular gastritis-like appearance $[9,35]$. In the present study, the three cases of gastric MALT lymphoma with nodular gastritis included the cases that were previously reported as gastric MALT lymphoma with a nodular gastritis-like appearance. In this study, gastric MALT lymphoma cases with NHPH infections more often tended to have nodules in the gastric mucosa relative to NHPH (-) cases. A possible cause of this nodule formation might be lymphoid hyperplasia, which NHPH infections have been reported to induce [16, 42, 43]. However, Iwamuro et al. reported two cases of $\mathrm{Hp}$-induced gastric MALT lymphoma with multiple whitish nodules in the gastric mucosa [44]. Thus, it is uncertain whether the nodular gastritis-like appearance of MALT lymphoma is specific to NHPH-induced gastric MALT lymphoma. Further studies with more cases should be performed to evaluate this observation.

In conclusion, this study is the first to show that the prevalence of NHPH infections was significantly greater in $H p(-)$ cases than in $H p(+)$ cases and that among $H p(-)$ cases, eradication therapy was more effective against $\mathrm{NHPH}(+)$ cases than against NHPH (-) cases. The efficacy of eradication therapy in some $H p(-)$ cases may be partly due to the involvement of NHPH infections. Eradication therapy may be a treatment option for some $H p(-)$ gastric MALT lymphoma cases as well, and NHPH infection status could 
be a useful predictive marker for the outcome of eradication therapy in $H p(-)$ gastric MALT lymphoma. Our data suggest that eradication therapy is a highly effective treatment choice in API2-MALT1 (-) and HP (-) gastric MALT lymphoma and could be recommended particularly in NHPH (+) cases, given the benefit of potentially avoiding RT and its side effects.

\section{Data availability statement}

The data that support the findings of this study are available from the corresponding author upon reasonable request.

Acknowledgements This research was partially supported by the PUH Research Grant Program (Advanced Research A). We would like to thank Editage (www.editage.jp) for the English-language editing.

Author contributions Conceptualization: HT, YK, and RY; Methodology: HT, YU, and SM; Project administration: SO; Investigation: RO, HK, TN, and RH; Writing — original draft preparation: HT; Writingreview and editing: YK and RY; Funding acquisition: YK; Supervision: ST and KC. All authors read and approved the final manuscript.

\section{Compliance with ethical standards}

Conflict of interest The authors declare that there is no conflict of interest regarding the publication of this paper.

Ethical approval The study was conducted in accordance with the Declaration of Helsinki and was approved by the Institutional Review Board of the Hiroshima University Hospital (IRB number; E-298).

Informed consent Informed consent was obtained in all cases.

\section{References}

1. Herrmann R, Panahon AM, Barcos MP, Walsh D, Stutzman L. Gastrointestinal involvement in non-Hodgkin's lymphoma. Cancer. 1980;46(1):215-22. https://doi.org/10.1002/1097-0142(19800 701)46:1\%3c215::aid-cncr2820460136\%3e3.0.co;2-6 (PubMed PMID: 7388763).

2. d'Amore F, Brincker H, Gronbaek K, Thorling K, Pedersen M, Jensen MK, et al. Non-Hodgkin's lymphoma of the gastrointestinal tract: a population-based analysis of incidence, geographic distribution, clinicopathologic presentation features, and prognosis. Danish Lymphoma Study Group. J Clin Oncol. 1994;12(8):1673-84. https://doi.org/10.1200/JCO.1994.12.8.1673 (PubMed PMID: 8040680).

3. Ghimire P, Wu GY, Zhu L. Primary gastrointestinal lymphoma. World J Gastroenterol. 2011;17(6):697-707. https://doi. org/10.3748/wjg.v17.i6.697 (PubMed PMID: 21390139; PubMed Central PMCID: PMCPMC3042647).

4. Nakamura S, Matsumoto T. Helicobacter pylori and gastric mucosa-associated lymphoid tissue lymphoma: recent progress in pathogenesis and management. World J Gastroenterol. 2013;19(45):8181-7. https://doi.org/10.3748/wjg.v19.i45.8181 (PubMed PMID: 24363507; PubMed Central PMCID: PMCPMC3857439).
5. Morgner A, Lehn N, Andersen LP, Thiede C, Bennedsen M, Trebesius K, et al. Helicobacter heilmannii-associated primary gastric low-grade MALT lymphoma: complete remission after curing the infection. Gastroenterology. 2000;118(5):821-8. https://doi.org/10.1016/S0016-5085(00)70167-3 (PubMed PMID: WOS:000086836400005).

6. Okiyama Y, Matsuzawa K, Hidaka E, Sano K, Akamatsu T, Ota H. Helicobacter heilmannii infection: clinical, endoscopic and histopathological features in Japanese patients. Pathol Int. 2005;55(7):398-404. https://doi.org/10.111 1/j.1440-1827.2005.01844.x (PubMed PMID: 15982214).

7. O'Rourke JL, Dixon MF, Jack A, Enno A, Lee A. Gastric B-cell mucosa-associated lymphoid tissue (MALT) lymphoma in an animal model of "Helicobacter heilmannii" infection. J Pathol. 2004;203(4):896-903. https://doi.org/10.1002/path.1593 (PubMed PMID: 15258991).

8. Haesebrouck F, Pasmans F, Flahou B, Chiers K, Baele M, Meyns $\mathrm{T}$, et al. Gastric helicobacters in domestic animals and nonhuman primates and their significance for human health. Clin Microbiol Rev. 2009;22(2):202-23. https://doi.org/10.1128/ CMR.00041-08 (Table of Contents. PubMed PMID: 19366912; PubMed Central PMCID: PMCPMC2668234).

9. Nakamura M, Overby A, Michimae H, Matsui H, Takahashi S, Mabe K, et al. PCR analysis and specific immunohistochemistry revealing a high prevalence of non-Helicobacter pylori Helicobacters in Helicobacter pylori-negative gastric disease patients in Japan: high susceptibility to an Hp eradication regimen. Helicobacter. 2020;25(5):e12700. https://doi.org/10.1111/ hel.12700 (PubMed PMID: 32790220).

10. Debongnie JC, Donnay M, Mairesse J, Lamy V, Dekoninck X, Ramdani B. Gastric ulcers and Helicobacter heilmannii. Eur J Gastroenterol Hepatol. 1998;10(3):251-4. https://doi. org/10.1097/00042737-199803000-00011 (PubMed PMID: 9585030).

11. Joo M, Kwak JE, Chang SH, Kim H, Chi JG, Kim KA, et al. Helicobacter heilmannii-associated gastritis: clinicopathologic findings and comparison with Helicobacter pylori-associated gastritis. J Korean Med Sci. 2007;22(1):63-9. https://doi. org/10.3346/jkms.2007.22.1.63 (PubMed PMID: 17297253; PubMed Central PMCID: PMCPMC2693570).

12. Holck S, Ingeholm P, Blom J, Norgaard A, Elsborg L, Adamsen $\mathrm{S}$, et al. The histopathology of human gastric mucosa inhabited by Helicobacter heilmannii-like (Gastrospirillum hominis) organisms, including the first culturable case. APMIS. 1997;105(10):746-56. https://doi. org/10.1111/j.1699-0463.1997.tb05080.x (PubMed PMID: 9368589).

13. Ierardi E, Monno RA, Gentile A, Francavilla R, Burattini O, Marangi S, et al. Helicobacter heilmannii gastritis: a histological and immunohistochemical trait. J Clin Pathol. 2001;54(10):7747. https://doi.org/10.1136/jcp.54.10.774 (PubMed PMID: 11577125; PubMed Central PMCID: PMCPMC1731280).

14. Morgner A, Bayerdorffer E, Neubauer A, Stolte M. Malignant tumors of the stomach. Gastric mucosa-associated lymphoid tissue lymphoma and Helicobacter pylori. Gastroenterol Clin North Am. 2000;29(3):593-607 (PubMed PMID: 11030075).

15. Enno A, O'Rourke JL, Howlett CR, Jack A, Dixon MF, Lee A. MALToma-like lesions in the murine gastric mucosa after long-term infection with Helicobacter felis A mouse model of Helicobacter pylori-induced gastric lymphoma. Am J Pathol. 1995;147(1):217-22 (PubMed PMID: 7604881; PubMed Central PMCID: PMCPMC1869885).

16. Goji S, Tamura Y, Sasaki M, Nakamura M, Matsui H, Murayama SY, et al. Helicobacter suis-Infected nodular gastritis and a review of diagnostic sensitivity for Helicobacter heilmannii-like organisms. Case Rep Gastroenterol. 2015;9(2):179-87. https:// 
doi.org/10.1159/000431169 (PubMed PMID:26120299; PubMed Central PMCID: PMCPMC4478311).

17. Heilmann KL, Borchard F. Gastritis due to spiral shaped bacteria other than Helicobacter-Pylori-clinical, histological, and ultrastructural findings. Gut. 1991;32(2):137-40. https://doi.org/10.1136/gut.32.2.137 (PubMed PMID: WOS:A1991EW53800005).

18. Solnick JV, Orourke J, Lee A, Paster BJ, Dewhirst FE, Tompkins LS. An uncultured gastric spiral organism is a newly identified helicobacter in humans. J Infect Dis. 1993;168(2):379-85. https://doi.org/10.1093/infdis/168.2.379 (PubMed PMID: WOS:A1993LN81300018).

19. De Groote D, van Doorn LJ, Ducatelle R, Verschuuren A, Haesebrouck F, Quint WGV, et al. "Candidatus Helicobacter suis", a gastric helicobacter from pigs, and its phylogenetic relatedness to other gastrospirilla. Int J Syst Bacteriol. 1999;49:1769-77. https://doi.org/10.1099/00207713-49-4-1769 (PubMed PMID: WOS:000083450800050).

20. Baele M, Decostere A, Vandamme P, Ceelen L, Hellemans A, Mast $\mathrm{J}$, et al. Isolation and characterization of Helicobacter suis sp nov from pig stomachs. Int J Syst Evol Micr. 2008;58:1350 8. https://doi.org/10.1099/ijs.0.65133-0 (PubMed PMID: WOS:000257277200014).

21. O'Rourke JL, Solnick JV, Neilan BA, Seidel K, Hayter R, Hansen LM, et al. Description of "Candidatus Helicobacter heilmannii" based on DNA sequence analysis of 16S rRNA and urease genes. Int J Syst Evol Micr. 2004;54:2203-11. https://doi.org/10.1099/ijs.0.63117-0 (PubMed PMID: WOS:000225366000052).

22. Smet A, Flahou B, D'Herde K, Vandamme P, Cleenwerck I, Ducatelle R, et al. Helicobacter heilmannii sp. Nov., isolated from feline gastric mucosa. Int J Syst Evol Micr. 2012;62:1016. https://doi.org/10.1099/ijs.0.68146-0 (PubMed PMID: WOS:000303487100048).

23. Masaki S, Takigawa H, Kunisho S, Kimoto A, Yuge R, Tanaka $\mathrm{S}$, et al. Association between Helicobacter suis infection and the pathogenesis of gastric mucosa-associated lymphoid tissue lymphoma. Hiroshima J Med Sci. 2020;69(2):33-7. https://doi. org/10.24811/hjms.69.2_33.

24. Asano N, Iijima K, Koike T, Imatani A, Shimosegawa T. Helicobacter pylori-negative gastric mucosa-associated lymphoid tissue lymphomas: a review. World J Gastroenterol. 2015;21(26):801420. https://doi.org/10.3748/wjg.v21.i26.8014 (PubMed PMID: 26185372; PubMed Central PMCID: PMCPMC4499343).

25. Choi YJ, Kim N, Paik JH, Kim JM, Lee SH, Park YS, et al. Characteristics of Helicobacter pylori-positive and Helicobacter pylori-negative gastric mucosa-associated lymphoid tissue lymphoma and their influence on clinical outcome. Helicobacter. 2013;18(3):197-205. https://doi.org/10.1111/hel.12033 (PubMed PMID: 23305046).

26. Nakamura S, Sugiyama T, Matsumoto T, Iijima K, Ono S, Tajika $\mathrm{M}$, et al. Long-term clinical outcome of gastric MALT lymphoma after eradication of Helicobacter pylori: a multicentre cohort follow-up study of 420 patients in Japan. Gut. 2012;61(4):507-13. https://doi.org/10.1136/gutjnl-2011-300495 (PubMed PMID: 21890816)

27. Swerdlow SH, Campo E, Pileri SA, Harris NL, Stein H, Siebert $\mathrm{R}$, et al. The 2016 revision of the World Health Organization classification of lymphoid neoplasms. Blood. 2016;127(20):2375-90. https://doi.org/10.1182/blood-2016-01-643569 (PubMed PMID: 26980727; PubMed Central PMCID: PMCPMC4874220).

28. Wotherspoon AC, Ortizhidalgo C, Falzon MR, Isaacson PG. Helicobacter-Pylori-associated gastritis and primary B-Cell GASTRIC LYMPHOMa. Lancet. 1991;338(8776):1175-6. https ://doi.org/10.1016/0140-6736(91)92035-Z (PubMed PMID: WOS:A1991GP03400007).
29. Copie-Bergman C, Gaulard P, Lavergne-Slove A, Brousse N, Flejou JF, Dordonne K, et al. Proposal for a new histological grading system for post-treatment evaluation of gastric MALT lymphoma. Gut. 2003;52(11):1656. https://doi.org/10.1136/ gut.52.11.1656 (PubMed PMID: WOS:000186070800023).

30. Musshoff K. Clinical staging classification of non-Hodgkin's lymphomas (author's trans1). Strahlentherapie. 1977;153(4):218-21 (PubMed PMID: 857349).

31. Streubel B, Lamprecht A, Dierlamm J, Cerroni L, Stolte M, Ott $\mathrm{G}$, et al. $\mathrm{T}(14 ; 18)(\mathrm{q} 32 ; \mathrm{q} 21)$ involving IGH and MALT1 is a frequent chromosomal aberration in MALT lymphoma. Blood. 2003;101(6):2335-9. https://doi.org/10.1182/blood-2002-092963 (PubMed PMID: WOS:000181432600041)

32. Akagi T, Motegi M, Tamura A, Suzuki R, Hosokawa Y, Suzuki $\mathrm{H}$, et al. A novel gene, MALT1 at $18 \mathrm{q} 21$, is involved in $\mathrm{t}(11 ; 18)$ (q21;q21) found in low-grade B-cell lymphoma of mucosaassociated lymphoid tissue. Oncogene. 1999;18(42):5785-94. https://doi.org/10.1038/sj.onc.1203018 (PubMed PMID: WOS:000083095100007).

33. Cho CJ, Kang HJ, Ryu YM, Park YS, Jeong HJ, Park YM, et al. Poor prognosis in Epstein-Barr virus-negative gastric cancer with lymphoid stroma is associated with immune phenotype. Gastric Cancer. 2018;21(6):925-35. https://doi.org/10.1007/ s10120-018-0820-3 (PubMed PMID: 29627937).

34. Liu J, He L, Haesebrouck F, Gong Y, Flahou B, Cao Q, et al. Prevalence of Coinfection with Gastric Non-Helicobacter pylori Helicobacter (NHPH) Species in Helicobacter pylori-infected Patients Suffering from Gastric Disease in Beijing, China. Helicobacter. 2015;20(4):284-90. https://doi.org/10.1111/hel.12201 (PubMed PMID: 25510739).

35. Takigawa H, Masaki S, Naito T, Yuge R, Urabe Y, Tanaka S, et $a l$. Helicobacter suis infection is associated with nodular gastritis-like appearance of gastric mucosa-associated lymphoid tissue lymphoma. Cancer Med. 2019;8(9):4370-9. https://doi. org/10.1002/cam4.2314 (PubMed PMID: 31210418; PubMed Central PMCID: PMCPMC6675707).

36. Kanda Y. Investigation of the freely available easy-to-use software 'EZR' for medical statistics. Bone Marrow Transplant. 2012;48:452. https://doi.org/10.1038/bmt.2012.244.

37. Jhala D, Jhala N, Lechago J, Haber M. Helicobacter heilmannii gastritis: association with acid peptic diseases and comparison with Helicobacter pylori gastritis. Mod Pathol. 1999;12(5):534-8 (PubMed PMID: 10349993).

38. Hilzenrat N, Lamoureux E, Weintrub I, Alpert E, Lichter M, Alpert L. Helicobacter heilmannii-like spiral bacteria in gastric mucosal biopsies. Prevalence and clinical significance. Arch Pathol Lab Med. 1995;119(12):1149-53 (PubMed PMID: 7503664).

39. Nakamura M, Murayama SY, Serizawa H, Sekiya Y, Eguchi $\mathrm{M}$, Takahashi $\mathrm{S}$, et al. "Candidatus Helicobacter heilmannii" from a cynomolgus monkey induces gastric mucosa-associated lymphoid tissue lymphomas in C57BL/6 mice. Infect Immun. 2007;75(3):1214-22. https://doi.org/10.1128/IAI.01459-06 (PubMed PMID: 17194807; PubMed Central PMCID: PMCPMC1828597).

40. Okamura T, Iwaya Y, Yokosawa S, Suga T, Arakura N, Matsumoto $\mathrm{T}$, et al. A case of Helicobacter heilmannii-associated primary gastric mucosa-associated lymphoid tissue lymphoma achieving complete remission after eradication. Clin J Gastroenterol. 2013;6(1):38-45. https://doi.org/10.1007/s 12328-0120355-9 (PubMed PMID: 26181403).

41. Yamamoto T, Matsumoto J, Shiota K, Kitajima S, Goto M, Imaizumi M, et al. Helicobacter heilmannii associated erosive gastritis. Intern Med. 1999;38(3):240-3. https://doi.org/10.2169/ internalmedicine.38.240 (PubMed PMID: 10337933). 
42. Peterson RA, Danon SJ, Eaton KA. Comparison of gastritis and gastric epithelial proliferation in Helicobacter heilmannii-infected nude and BALB/c mice. Vet Pathol. 2001;38(2):173-83. https:// doi.org/10.1354/vp.38-2-173 (PubMed PMID: 11280373).

43. Nobutani K, Yoshida M, Nishiumi S, Nishitani Y, Takagawa T, Tanaka H, et al. Helicobacter heilmannii can induce gastric lymphoid follicles in mice via a Peyer's patch-independent pathway. FEMS Immunol Med Microbiol. 2010;60(2):156-64. https:// doi.org/10.1111/j.1574-695X.2010.00731.x (PubMed PMID: 20846360).

44. Iwamuro M, Tanaka T, Nishida K, Kanzaki H, Kawano S, Kawahara Y, et al. Two cases of gastric mucosa-associated lymphoid tissue (MALT) lymphoma masquerading as follicular gastritis. Ecancermedicalscience. 2019;13:933. https://doi.org/10.3332/ ecancer.2019.933 (PubMed PMID: 31281430; PubMed Central PMCID: PMCPMC6605631).

Publisher's Note Springer Nature remains neutral with regard to jurisdictional claims in published maps and institutional affiliations. 